\title{
Quercetin Modulates Behavioural and Biochemical Alterations in Stressed Mice
}

\author{
Anthony Taghogho Eduviere ${ }^{1}$, Emuesiri Goodies Moke ${ }^{1}$, \\ Adrian Itivere Omogbiya ${ }^{1}$, Lily Oghenevovwero Otomewo ${ }^{1 *}$, \\ Juliet Nnenda Olayinka ${ }^{2}$, Faith Eninidiere Aboyewa ${ }^{1}$ and Atare Peace Ijeje ${ }^{1}$ \\ ${ }^{1}$ Department of Pharmacology, Delta State University, Abraka, Nigeria. \\ ${ }^{2}$ Department of Pharmacology, AfeBabalola University, Ado-Ekiti, Nigeria. \\ *Corresponding Author E-mail: ejirukomaotomewo@gmail.com \\ http://dx.doi.org/10.13005/bbra/2951
}

(Received: 27 October 2021; accepted: 30 November 2021)

\begin{abstract}
Disruption of the active phase of sleep alters the physiological homeostasis of the body and results in oxidative breakdown which may trigger a wide array of defects. The central nervous system and the metabolic system are some of the most affected systems as described in several literatures. Some plant based compounds with antioxidant property have been previously described in the abrogation of the deleterious effects of active sleep disruption. One of such compounds is quercetin. This study was premeditated to expatiate on the probable neuroprotective effect of quercetin on mice exposed to $72 \mathrm{hr}$ active sleep disruption. Mice were allotted into five treatment groups $(n=6)$ : group 1 served as control, group 2 received $10 \mathrm{~mL} / \mathrm{kg}$ vehicle, groups 3 and 4 received 25 and $50 \mathrm{mg} / \mathrm{kg}$ quercetin respectively, and group 5 received $50 \mathrm{mg} / \mathrm{kg}$ astaxanthin. Treatment lasted for 7 days while groups $2-5$ were exposed to the sleep deprivation protocol starting from day 4 . Behavioural tests followed by biochemical assays and histopathological changes in the prefrontal cortex were evaluated. Data were analysed by ANOVA set at $\mathbf{p}<0.05$ significance. The results revealed that quercetin, in both doses, significantly amplified memory performance, attenuated depression-like behaviour, replenished catalase and superoxide dismutase, attenuated nitric oxide levels in brain and liver of mice when compared to control group and protected against loss of prefrontal cortex neurons. In conclusion, quercetin possesses protective effects against sleep deprivation-induced brain damage.
\end{abstract}

Keywords: Antioxidants; Hepatoprotective; Liver; Neuroprotective; Oxidative stress; Quercetin.

Acute stress such as insufficient sleep is an infamous challenge in modern society, affecting a significant number of people at various points in their lives. Although occasional sleep disruptions are usually no more than a nuisance, persistent lack of sleep can lead to various alterations in bodily functions that may alter the quality of life ${ }^{1}$. Meanwhile, there are reports that acute stress increase oxidations and diminishes antioxidant protection particularly in the liver ${ }^{2}$.A similar ripple effect had previously been noted in the brain due to the relationship between the functional status of the liver and the brain ${ }^{3}$.

On the other hand, there is literary evidence on the neuroprotective effect of quercetin ${ }^{4}$.Several scientific literatures have shown that quercetin can bestow neuroprotection and antagonize oxidative stress-mediated disorders in vivo. For example, 
oral quercetin was revealed to protect laboratory animals from oxidative stress and neurotoxicity which were induced by various insults ${ }^{5,6}$. Also, Bona et al. ${ }^{7}$, reported that quercetin reversed the increase in serum levels of liver enzymes in rats caused by inhaled chloroform, supporting the belief that quercetin possesses antioxidant, hepatoprotective and neuroprotective ability. However, there is paucity of information on the role of quercetin in sleep deprivation-induced stress. Therefore, this study is justified in that it contributes to the body of literature on the probable modulatory effect of quercetin on behavioural and biochemical alterations in the brain and liver of sleep deprived mice.

\section{MATERIAL AND METHODS}

\section{Animals and Housing}

Male Albino Swiss mice $(n=30 ; 22.0 \pm 2.0$

g) used in this study were procured from the central animal facility, Faculty of BMS, Delta State University, Abraka. Mice were housed in plastic cages in groups of six and maintained under room temperature with a $12 \mathrm{~h}$ light-dark cycle (lights on from 07:00 to 19:00 hours). They were allowed access to water and rodent chow ad libitum. Note that mice were acclimatized for about one week before the experiment. The experimental protocols were performed according to the NIH guideline for laboratory animals with due approval from the ethical committee of the institution (REF/FBMS/ DELSU/21/105).

\section{Drugs and Chemicals}

Quercetin, astaxanthin and DTNB were obtained from Aldrich, Germany. Acetic acid was gotten from Sigma-Aldrich, Inc., St Louis, USA. TCA was obtained from Burgoyne Burbidge's\& Co., Mumbai, India.TBA and DMSO were obtained from Guanghua Chemical Factory Co. Ltd., China.Tris-buffer was obtained from Hopkins\& Williams Company, USA. $\mathrm{NaHCO}_{3}, \mathrm{NaH}_{2} \mathrm{PO}_{4}$. $\mathrm{H}_{2} \mathrm{O}, \mathrm{K}_{2} \mathrm{HPO}_{4}, \mathrm{~K}_{2} \mathrm{Cr}_{2} \mathrm{O}_{7}, \mathrm{KCl}$ and $\mathrm{Na}_{2} \mathrm{HPO}_{4} \cdot \mathrm{H}_{2} \mathrm{O}$ were obtained from BDH Chemicals Ltd, Poole, England. Sodium Carbonate was obtained from Fisons, Loughborough Leics, England. $\mathrm{NaOH}$ was obtained from J.T Baker Chemicals Co., Phillips burg, N.J., USA.

Drug Preparation and Treatment Groups

The concentrations of quercetin used in this study were obtained following a serial dilution of $100 \mathrm{mg}$ quercetin in $20 \mathrm{~mL}$ of $0.5 \%$ DMSO. The mice were indiscriminately distributed into five (5) treatment groups $(n=6)$ based on the drug they received: group 1 received vehicle $(10 \mathrm{~mL} /$ $\mathrm{kg} 0.5 \% \mathrm{DMSO}$, p.o), group 2 received vehicle in addition to being sleep-deprived, while group 3 received low-dose quercetin and group 4 received high-dose quercetin $(25 \mathrm{mg} / \mathrm{kg}$ and $50 \mathrm{mg} / \mathrm{kg} \mathrm{p.o}$, respectively) in addition to being sleep-deprived, group 5 received astaxanthin $(50 \mathrm{mg} / \mathrm{kg})$ in addition to being sleep-deprived. Total treatment duration was seven (7) days. From the fourth day, mice in groups 2-5 were subjected to $72 \mathrm{hr}$ sleep deprivation.

\section{Experimental Design}

Deprivation of the active stage of sleep was carried out in line with the method of Shinomiya and colleagues ${ }^{8}$ with moderate modifications.

At the end of the $72 \mathrm{hr}$ sleep deprivation duration, $1 \mathrm{hr}$ after the last treatment, the effect of active sleep deprivation on behaviour, hepatic/ brain oxidative stress parameters and lipid profile was assessed. Also, animals were euthanized on the seventh day. Liver and brain tissues were harvested and specific tissues were kept aside for histopathological evaluation.

\section{Behavioural Tests \\ Open field test (OFT)}

The OFT was used to determine the spontaneous motor activity (SMA) of mice following the method described ${ }^{9} 10$. Number of square lines crossed and duration of ambulation of each mouse was recorded within a10 min period.

\section{Tail suspension test(TST)}

The TST was carried out in accordance with the procedure described ${ }^{11}$ with slight changes. A mouse was adjudged to be non-mobile if it made no movements with its head above water level.

\section{Novel object recognition test}

The novel object recognition memory test explores the animal's preference for novelty. In this study, the method described ${ }^{12}$ was followed. The percentage preference, which was used as an index of recognition memory, was calculated as the total time spent by a mouse in exploring the novel object divided by the summation of total time spent exploring both the familiar and novel objects multiplied by $100 \%$. 


\section{Assessment of lipid profile \\ Serum triglyceride levels}

Serum triglyceride level in mouse serum was determined by enzymatic colorimetric method according to the protocol earlier described ${ }^{13}$. Concentration of triglyceride $(\mathrm{mg} / \mathrm{dL})$ in the sample was obtained from the equation:

$\mathrm{C}_{\mathrm{X}}=\left[\mathrm{K}\left(\mathrm{A}_{\mathrm{X}}-\mathrm{A}_{\mathrm{b}}\right)+\mathrm{C}_{\mathrm{b}}\right] \mathrm{x}$ IF

Where:

$\mathrm{C}_{\mathrm{x}}=$ Concentration of sample

$\mathrm{K}=$ Concentration factor

$A_{x}=$ Mean of absorbance of Sample

$A_{b}=$ Mean of absorbance of blank

$\mathrm{C}_{\mathrm{b}}=$ concentration of blank

$\mathrm{IF}=$ instrument factor (or dilution correction)

High-density lipoproteins

High-density lipoproteins (HDL)level was determined in mouse serum by enzymatic colorimetric method according to the protocol described ${ }^{13}$. Concentration of $\mathrm{HDL}(\mathrm{mg} / \mathrm{dL})$ in the sample is obtained from the equation:

$\mathrm{C}_{\mathrm{X}}=\left[\mathrm{K}\left(\mathrm{A}_{\mathrm{X}}-\mathrm{A}_{\mathrm{b}}\right)+\mathrm{C}_{\mathrm{b}}\right] \mathrm{x}$ IF

Where:

$\mathrm{C}_{\mathrm{x}}=$ Concentration of sample

$\mathrm{K}=$ Concentration factor

$A_{x}=$ Mean of absorbance of Sample

$A_{b}=$ Mean of absorbance of blank

$\mathrm{C}_{\mathrm{b}}=$ concentration of blank

$\mathrm{IF}=$ instrument factor (or dilution correction)
Biochemical Assays

Superoxide dismutase (SOD) activity approximation

The level of SOD activity in the brain and liver was approximated according to the method modified by Umukoro and his colleagues ${ }^{14}$ which involves the use of adrenaline. This activity was expressed in units of adrenaline consumed per minute per mg protein.

\section{Estimation of catalase (CAT) activity}

Brain and liver catalase activity was determined according to the Hadwan method ${ }^{15}$. The catalase activity was expressed in $\mu \mathrm{mol}$.

Estimation of nitric oxide

Brain and liver nitrite concentration was estimated following the method of Green et al. ${ }^{16}$, which involves the use of Greiss reagent.

\section{Statistical Analysis}

Data sets were presented as Mean \pm S.E.M. The results were analysed using the oneway ANOVA technique, and a specific post hoc test (Student's Newman-Keuls) was carried out to determine the criterion of significance using Graph Pad Biostatistics software. Significance for all tests was then established at $p<0.05$.

\section{RESULTS AND DISCUSSION}

This study was undertaken to assess the effect of active sleep deprivation alone and

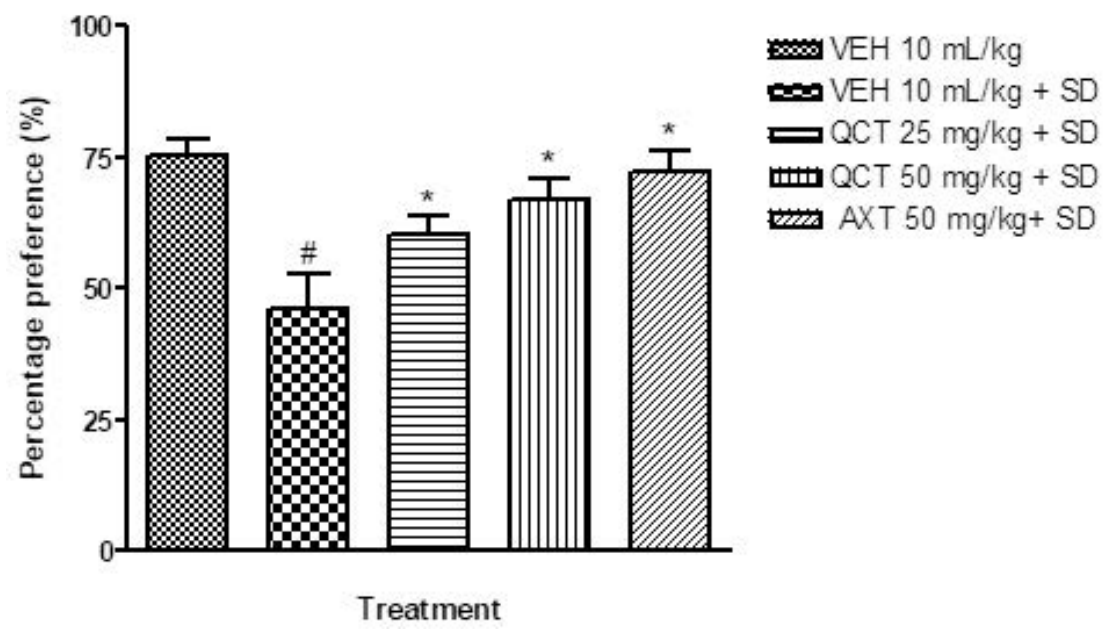

\# depicts significance $(\mathrm{p}<0.05)$ compared to non sleep-deprived group.

* depicts significance $(\mathrm{p}<0.05)$ compared to vehicle + SD group.

VEH: Vehicle. AXT: Astaxanthin. QCT: Quercetin. SD: Sleep deprivation.

Fig. 1. Effect of quercetin on recognition memory in sleep deprived mice 

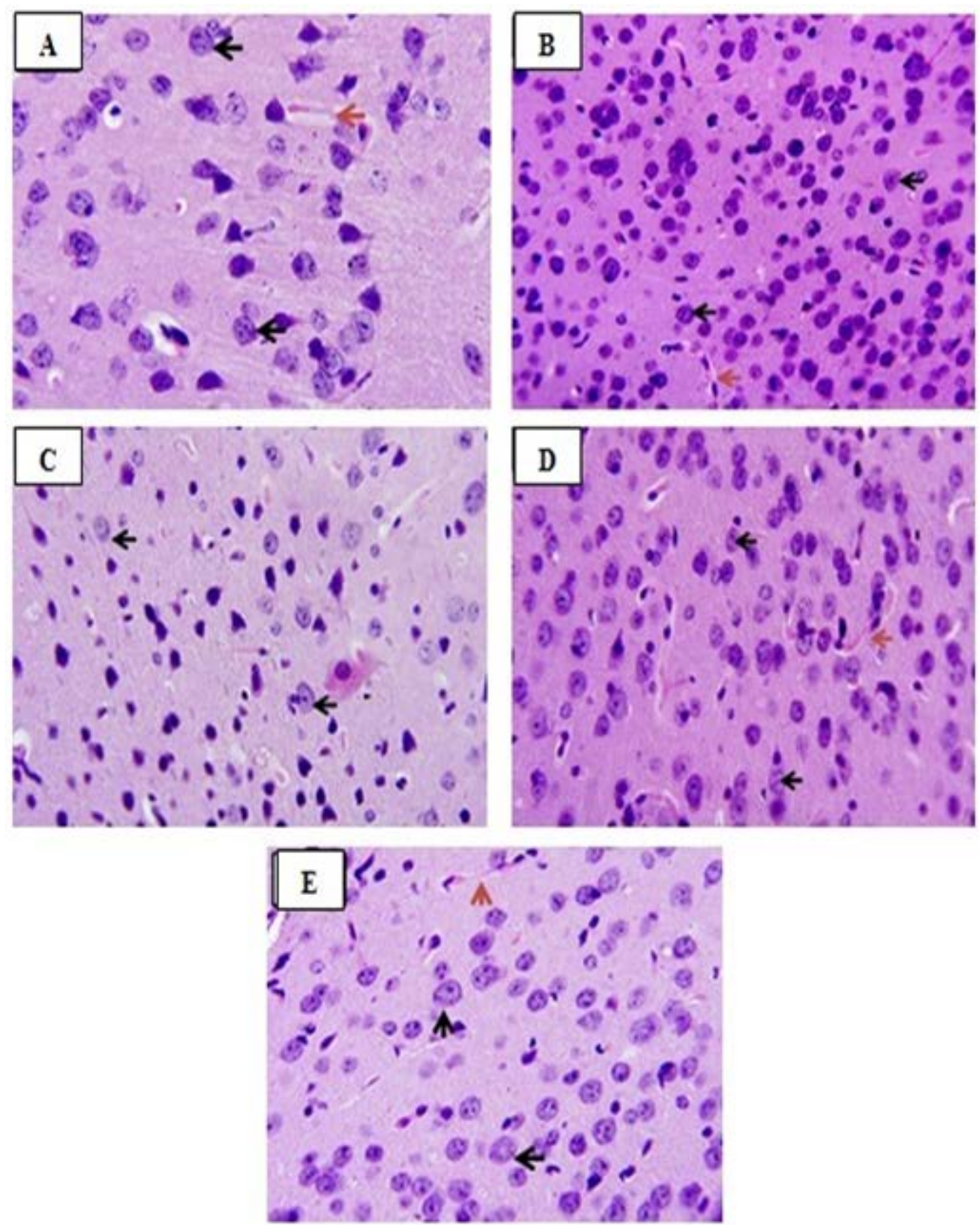

Slide A: Non-sleep deprived group, VEH $10 \mathrm{~mL} / \mathrm{kg}$.

Slide B: Sleep deprived group, VEH $10 \mathrm{~mL} / \mathrm{kg}+\mathrm{SD}$.

Slide C: Low-dose quercetin group, QCT $25 \mathrm{mg} / \mathrm{kg}+\mathrm{SD}$.

Slide D: High-dose quercetin group, QCT $50 \mathrm{mg} / \mathrm{kg}+\mathrm{SD}$.

Slide E: Astaxanthin group, AXT $50 \mathrm{mg} / \mathrm{kg}+\mathrm{SD}$.

Black arrows: Normal neuronal cells.

Red arrows: Neuronal cells undergoing necrosis.

VEH: Vehicle. AXT: Astaxanthin. QCT: Quercetin. SD: Sleep deprivation.

Fig. 2. Photomicrograph of the prefrontal cortex of sleep deprived mice 
in combination with quercetin supplementation on brain and liver oxidative stress status and behavioural phenotypes in mice. There are many mechanisms via which sleep deprivation can be responsible for oxidative consequences and liver toxicity, but these effects are probably not attributable to a single night of sleep deprivation. In this study, we measured the effects of $72 \mathrm{hr}$ sleep deprivation on lipid profile parameters, hepatic and brain oxidative stress biomarkers, anxietylike symptoms, depression-like behaviour and recognition memory consolidation in mice.

The results of this study showed that sleep deprivation significantly diminished recognition memory, as it decreased the percentage preference for the familiar object in mice (Figure 1). Recognition memory was impaired in the sleep deprived group with a significant reduction in percentage preference in the novel object recognition paradigm when compared to the nonsleep-deprived group. Traditionally, the usefulness of this test in memory assessment is based on the innate inclination of animals (particularly rodents) for unfamiliar objects ${ }^{12}$. The preference of mice for a novel object as compared to a familiar one indicates the existence of the object's familiarity in the animals' memory. Thus, the duration of exploration depends on the degree of residual memory of the object. In this test, quercetin increased the duration of exploration of the novel object, which suggests memory improvement ${ }^{12}$.

Quercetin also protects neuronal cells. This was substantiated in this study by histomorphometric analysis of the prefrontal cortex

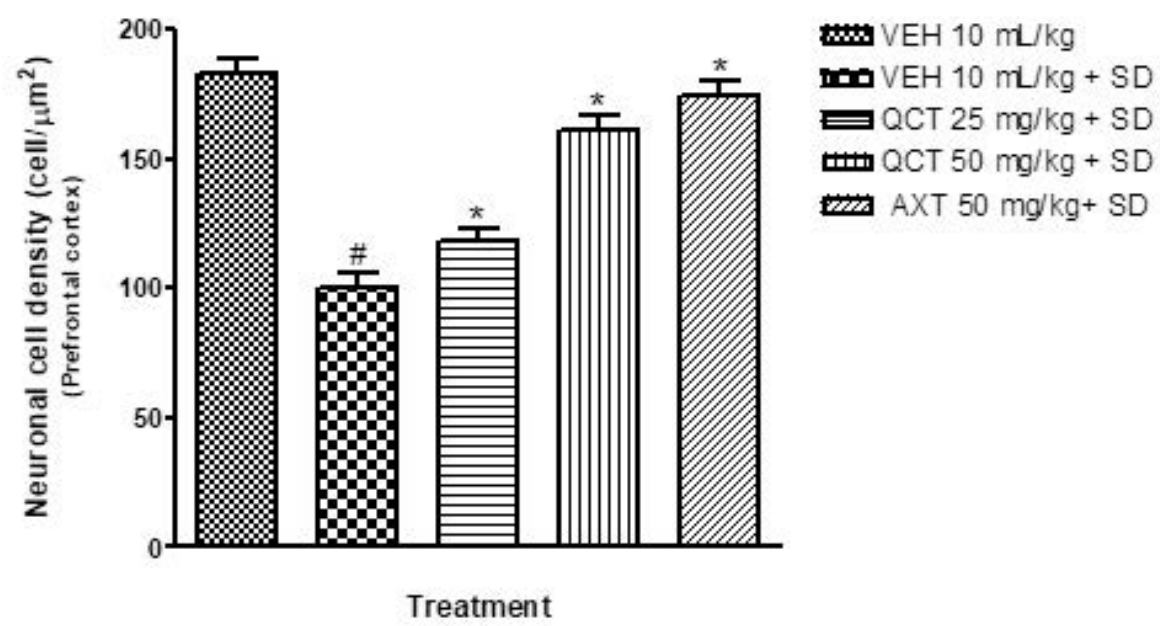

\# depicts significance $(\mathrm{p}<0.05)$ compared to non sleep-deprived group.

* depicts significance $(\mathrm{p}<0.05)$ compared to vehicle + SD group.

VEH: Vehicle. AXT: Astaxanthin. QCT: Quercetin. SD: Sleep deprivation.

Fig. 3. Effect of quercetin on viable prefrontal cortex neurons in sleep-deprived mice

Table 1. Effect of quercetin on brain oxidative stress parameters in sleep deprived mice

\begin{tabular}{lccc}
\hline Treatment & $\begin{array}{c}\text { CAT } \\
\text { (units/mg protein) }\end{array}$ & $\begin{array}{c}\text { SOD } \\
\text { (units/mg protein) }\end{array}$ & NO $(\mu \mathrm{M})$ \\
\hline VEH 10 mL/kg & $33.47 \pm 1.93$ & $16.91 \pm 0.62$ & $47.37 \pm 4.55$ \\
VEH 10 mL/kg +SD & $15.87 \pm 1.94^{\#}$ & $10.32 \pm 0.95^{\#}$ & $76.59 \pm 6.37^{\#}$ \\
QCT 25 mg/kg +SD & $28.88 \pm 3.81^{*}$ & $16.93 \pm 0.86^{*}$ & $51.65 \pm 3.01^{*}$ \\
QCT 50 mg/kg +SD & $32.60 \pm 3.71^{*}$ & $20.67 \pm 0.94^{*}$ & $39.77 \pm 4.45^{*}$ \\
AXT 50 mg/kg +SD & $27.10 \pm 1.88^{*}$ & $15.61 \pm 1.07^{*}$ & $42.34 \pm 5.14^{*}$ \\
\hline
\end{tabular}

\# depicts significance $(\mathrm{p}<0.05)$ compared to non sleep-deprived group.

* depicts significance $(\mathrm{p}<0.05)$ compared to vehicle + SD group.

VEH: Vehicle. AXT: Astaxanthin. QCT: Quercetin. SD: Sleep deprivation. 
of mice ${ }^{17}$. The data revealed that sleep deprived mice had significant necrosis of brain cells (slide B) when compared with the non-sleep deprived group (slide A). This was similar to the observed changes in neuronal densitities of the prefrontal cortex of mice in all groups ${ }^{18}$. This was reversed by quercetin supplementation (slides $\mathrm{C}$ and $\mathrm{D}$; Figure 2 and 3 ) as effectively as astaxanthin (slide E). This could also play a role in the memory impairment observed since a study by Umukoro and Eduviere ${ }^{19}$ had implicated the prefrontal cortex as one of the notable brain regions with a role in recognition memory. Although more preclinical studies are necessary before commenting on how quercetin improves memory in mice, the present data suggest modulatory effect of quercetin on sleep deprivation-induced recognition memory impairment.

Also from this study, recognition memory impairment caused by sleep deprivation was accompanied by increased brain oxidative stress, as indicated by elevated levels of nitrite and decreased antioxidant defence systems in the brain (Table 1). In the brain tissue of the sleep deprived group, SOD and CAT activity were significantly $(\mathrm{p}<0.05)$ lower, whereas nitrite levels was significantly increased $(\mathrm{p}$ $<0.05$ ) when compared to the control group. This effect was however attenuated by quercetin pre-

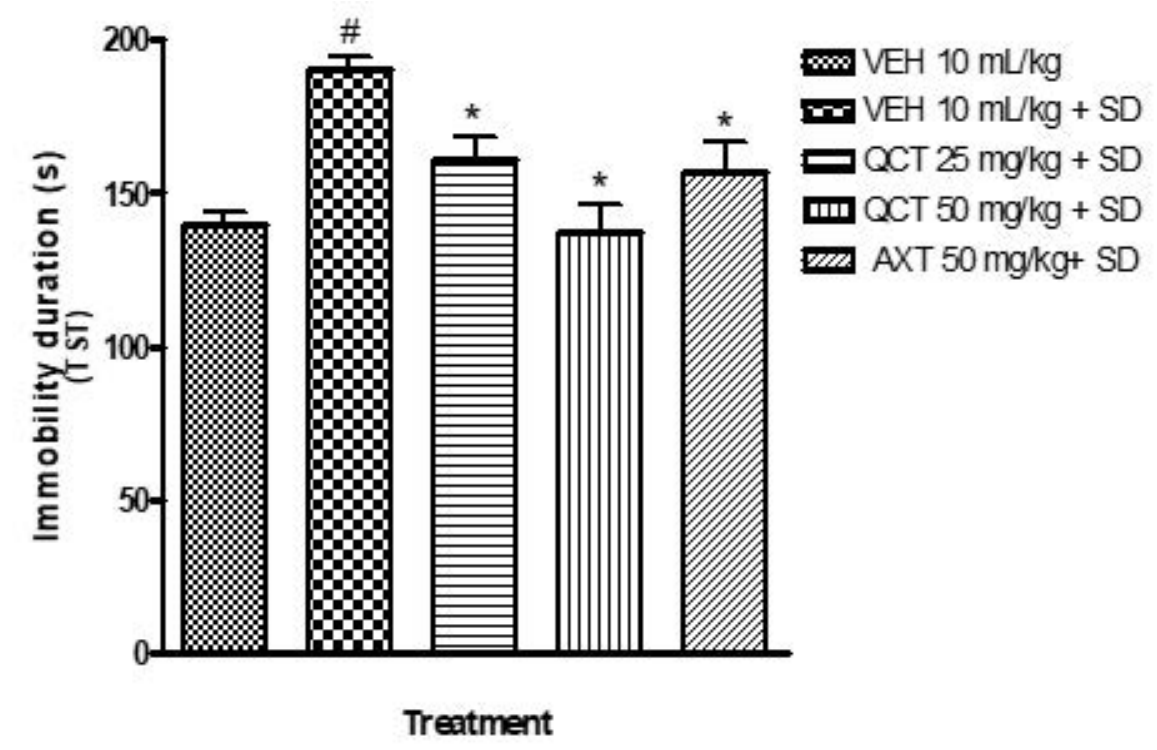

\# depicts significance $(\mathrm{p}<0.05)$ compared to non sleep-deprived group.

* depicts significance $(\mathrm{p}<0.05)$ compared to vehicle + SD group.

VEH: Vehicle. AXT: Astaxanthin. QCT: Quercetin. SD: Sleep deprivation.

Fig. 4. Effect of quercetin on depression-like behaviour in sleep-deprived mice

Table 2. Effect of quercetin on spontaneous motor activity in sleep deprived mice

\begin{tabular}{lcc}
\hline Treatment & Number of lines crossed & Ambulation (min) \\
\hline VEH $10 \mathrm{~mL} / \mathrm{kg}$ & $143.70 \pm 8.19$ & $3.52 \pm 0.36$ \\
VEH $10 \mathrm{~mL} / \mathrm{kg}+\mathrm{SD}$ & $213.50 \pm 10.22^{\#}$ & $6.88 \pm 0.39^{\#}$ \\
QCT $25 \mathrm{mg} / \mathrm{kg}+\mathrm{SD}$ & $175.50 \pm 13.18^{*}$ & $4.80 \pm 0.38^{*}$ \\
QCT $50 \mathrm{mg} / \mathrm{kg}+\mathrm{SD}$ & $165.70 \pm 7.66^{*}$ & $4.34 \pm 0.46^{*}$ \\
AXT $50 \mathrm{mg} / \mathrm{kg}+\mathrm{SD}$ & $185.50 \pm 4.87^{*}$ & $5.09 \pm 0.28^{*}$ \\
\hline
\end{tabular}

\# depicts significance $(\mathrm{p}<0.05)$ compared to non sleep-deprived group.

* depicts significance $(\mathrm{p}<0.05)$ compared to vehicle + SD group.

VEH: Vehicle. AXT: Astaxanthin. QCT: Quercetin. SD: Sleep deprivation. 
treatment as effectively as astaxanthin. This is in line with previous studies ${ }^{19,20}$. Thus, the capability of quercetin to reverse sleep deprivation-induced memory impairment in mice suggests an action that may involve the inhibition of central oxidative stress. This action possibly resulted from its ability to replenish antioxidant defence systems (SOD and catalase) and decrease NO levels. .

Furthermore, other mood-related behaviours (depression and anxiety) were assessed in this study. Sleep deprived mice were more active in the open field test (Table 2), signalling anxiety; and increased duration of immobile state in the TST (Figure 4), signalling depression. Sleep deprivation significantly $(\mathrm{p}<0.05)$ diminished the motor activity of mice as shown in less number of lines crossed and duration of ambulation and significantly $(p<0.05)$ increased the immobility time of mice in the TST when compared to the non-sleep deprived group. However, quercetintreated groups exhibited improved mood recorded as increased number of lines crossed in the open field test and decreased duration of immobility in the TST. This agrees with previous studies which have outlined the beneficial role of quercetin on anxiety- and depressive-like symptoms ${ }^{22}$.

Also in this study, triglyceride level was significantly $(\mathrm{p}<0.05)$ elevated while high-density lipoprotein was significantly $(\mathrm{p}<0.05)$ diminished in the sleep deprived group (Table 3 ). Literary evidence has associated sleep disorders with serious complications like type 2 diabetes mellitus ${ }^{23}$ and glucose intolerance or insulin resistance ${ }^{24}$.The liver which is the site of metabolism is particularly vulnerable to oxidative stress thus predisposing the organism to further damage ${ }^{25,26}$. Results from this study also support this evidence with sleep deprived mice showing a significant $(\mathrm{p}<0.05)$ elevation in nitrite levels and decrease in antioxidant levels (Table 4). The administration of quercetin in sleep deprived mice was able to attenuate these deleterious effects of sleep deprivation.

Table 3. Effect of quercetin on triglyceride and high-density lipoprotein levels in sleep deprived mice

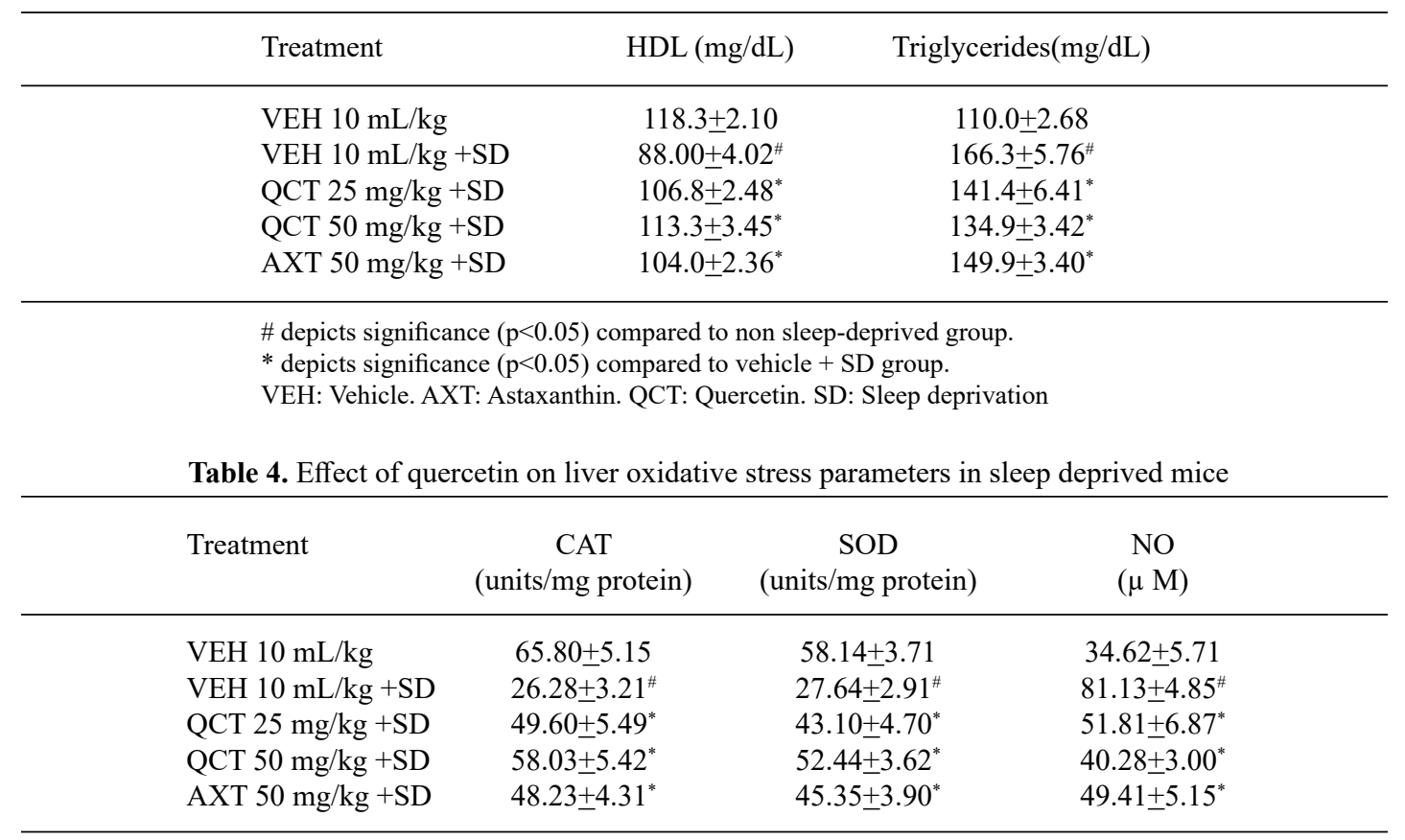

\# depicts significance $(\mathrm{p}<0.05)$ compared to non sleep-deprived group.

$*$ depicts significance $(\mathrm{p}<0.05)$ compared to vehicle + SD group.

VEH: Vehicle. AXT: Astaxanthin. QCT: Quercetin. SD: Sleep deprivation. 


\section{CONCLUSIONS}

Based on the antioxidant and protective effects of quercetin on the brain and liver of mice in this study, we believe that this compound stands a chance of being a potential therapeutic agent for the treatment of neuronal degeneration resulting from sleep deprivation. Nevertheless, more reliable methods such as immunocytochemistry are recommended for further investigation of the neuroprotective effect of quercetin.

\section{ACKNOWLEDGEMENT}

We appreciate the technical support of the laboratory personnel of Pharmacology department. Also, we give special gratitude to Mr. Adedamola Fafure for the histology.

\section{Conflict of Interest}

The authors declare the absence of conflicts of interest

\section{Funding support}

The authors received no external funding for this research

\section{REFERENCES}

1. Carley D. W. and Farabi S. S. Physiology of sleep. Diabetes Spectr. 2016; 29(1): 5-9.

2. Zhai B, Wu C, Wang L, Sachs M. S. and Lin $\mathrm{X}$. The antidepressant sertraline provides a promising therapeutic option for neurotropic cryptococcal infections. Antimicrob Agents Chemother, 2012; 56(7):3758-3766.

3. Jones E. A. and Weissenborn K. Neurology and the liver. Journal of Neurology, Neurosurgery and Psychiatry, 1997; 63:279-293.

4. Ossola B, Kaariaiinen T. M. and Mannisto P. T. The multiple faces of quercetin in neuroprotection. Expert Opinion on Drug Safety, 2009; 8(4):397-409.

5. Ishisaka A, Ichikawa S, Sakakibara H, et al. Accumulation of orally administered quercetin in brain tissue and its antioxidative effects in rats. Free Radical Biology and Medicine, 2011; 51(7); 1329-1336.

6. Das S, Mandal A. K, Ghosh A, Panda S, Das N. and Sarkar S. Nanoparticulatedquercetin in combating age related cerebral oxidative injury. Current Aging Science, 2008; 1(3); 169-174

7. Bona S, Filippin L. I, Di Naso F. C, et al. Effect of antioxidant treatment on fibrogenesis in rats with carbon tetrachloride-induced cirrhosis.
ISRN Gastroenterol 2012; 762920.

8. Shinomiya K, Shigemoto Y, Okuma C, Mio M. and Kamei C. Effects of short-acting hypnotics on sleep latency in rats placed on grid suspended over water. European Journal of Pharmacology, 2003; 460:139-144.

9. Adeoluwa O. A, Aderibigbe A. O, Agu G. O, Adewole F. A. and Eduviere A. T. Neurobehavioral and analgesic properties of ethanol bark extract of Terminaliaivorensis A Chev. (Combrataceae) in mice. Drug Res, 2015; 65;545-551

10. Annafi O. S, Aluko O. M, Eduviere A. T, Omorogbe O. and Umukoro S. Probable mechanisms involved in the antipsychoticlike activity of methyl jasmonate in mice. Naunyn-Schmiedeberg's Arch Pharmacol, 2017; 390:883-892

11. Adebesin A, Adeoluwa O. A, Eduviere A. T. and Umukoro S. Methyl jasmonate attenuated lipopolysaccharide-induced depressive-like behaviour in mice. Journal of Psychiatric Research, 2017; 94;29-35

12. Eduviere A. T, Umukoro S, Adeoluwa O. A, Omogbiya I. A. and Aluko O. M. Possible mechanisms involved in attenuation of lipopolysaccharide-induced memory deficits by methyl jasmonate in mice. Neurochem Res, 2016; 41:3239-3249

13. Bucolo G. and David H. Quantitative determination of serum triglycerides by use of enzymes. Clinical chemistry, 1973; 19: 476-482.

14. Umukoro S, Aluko OM, Eduviere AT, Owoeye O. Evaluation of adaptogenic-like property of methyl jasmonate in mice exposed to unpredictable chronic mild stress. Brain Res Bull. 2016;121:105-114.

15. HadwanM. New method for assessment of serum catalase activity. Indian Journal of Science and Technology, 2016; 9(4):1.

16. Green L. C, Wagner D. A, Glogowski J, Skipper P. L, Wishnok J. S. and Tannenbaum S. R. Analysis of nitrate, nitrite, and $[15 \mathrm{~N}]$ nitrate in biological fluids. Anal Biochem, 1982; 126(1): 131-138.

17. Garman R. H, Li A. A, Kaufmann W, Auer R.N. and Bolon B. Recommended methods for brain processing and quantitative analysis in rodent developmental neurotoxicity studies. Toxicologic Pathology, 2016; 44(1): 14-42.

18. Keller D, Ero C. and Markram H. Cell denisities in the mouse brain: a systematic review. Front. Neuroanat. 2018. Accessed from https://doi. org/10.3389/fnana.2018.00083

19. Umukoro S. and Eduviere A. T. Methyl jasmonate attenuates memory dysfunction and decreases 
brain levels of biomarkers of neuroinflammation induced by lipopolysaccharide in mice. Brain Research Bulletin, 2017; 131; 133-141

20. Reimund E. The free radical flux theory of sleep. Medical Hypotheses, 1994; 43(4);231-233.

21. Villafuerte G, Miguel-Puga A, Rodriguez E. M, Machado S, Manjarrez E. and Arias-Carrion O. Sleep deprivation and oxidative stress in animal models: a systematic review. Oxidative Medicine and Cellular Longevity, 2015; 234952.

22. Samad N, Saleem A, Yasmin F. and Shehzad M. A. Quercetinprotect against stress-induced anxiety- and depression-like behaviour and improve memory in male mice. Physiol. Res. 2018; 67: 795-808.

23. Khandelwal D, Dutta D, Chittawar S. and Kalra S. Sleep disorders in type 2 diabetes. Indian $J$ Endocrinol Metab, 2017; 21(5):758-761.
24. Hargens T. A, Kaleth A. S, Edwards E. S. and Butner K. L. Association between sleep disorders, obesity, and exercise: a review. Nat Sci Sleep 2013; 5:27-35.

25. Umukoro S, Oluwole O, Olamijowon H, Omogbiya A. I. and Eduviere A. T. Effect of MSG on behavioural phenotypes, biomarkers of oxidative stress in brain tissues and liver enzymes in mice. World Journal of Neuroscience, 2015; 5:339-349.

26. Omogbiya A. I, Ben-Azu B, Eduviere A. T, Eneni A. O, Nwokoye P. O, Ajayi A. M and Umukoro S. Monosodium glutamate induces memory and hepatic dysfunctions in mice: ameliorative role of Jobelyn ${ }^{\circledR}$ through the augmentation of cellular antioxidant defence machineries. Toxicol. Res, 2020; 37(2):1-15. 